\title{
Locating Personal Pedagogical Content Knowledge of Science Teachers within Stories of Teaching Force and Motion
}

\author{
Saiqa Azam ${ }^{1 *}$ \\ ${ }^{1}$ Memorial University of Newfoundland, CANADA
}

Received 28 June 2020 • Accepted 9 August 2020

\begin{abstract}
A narrative inquiry approach was adapted to study teacher's experiences of planning and teaching force and motion topics. Oral narrative data were collected through interview conversations between the researcher and the teachers about their experiences of planning and teaching force and motion concepts. Narrative analysis technique suggested by Polkinghorne, was employed to develop stories of teaching force and motion-that acceded access to their pPCK. and comprised of small entities of knowledge-pedagogical constructions, which are narrative fragments. Each pedagogical construction was placed on a four-level PCK continuum to assess the breadth and depth of each teacher's pPCK. A mapping technique was devised to illustrate pPCK of each participant teacher, and a comparative analysis of these illustrations reveals fascinating similarities and differences apparently grounded in individual teacher's subject area background and their specific teaching experiences. Implications for pre-service science teacher education are discussed.
\end{abstract}

Keywords: Pedagogical Content Knowledge (PCK), personal Pedagogical Content Knowledge (pPCK), Topic-Specific Pedagogical Content Knowledge (TSPCK), Topic-Specific Pedagogical Constructions (TSPC)

\section{INTRODUCTION}

Teachers hold professional knowledge of teaching, like any other professionals such as doctors, engineers and so on, which they acquire through years of experiences of teaching. Validating teaching as a practice-based profession and to represent teachers' professional knowledge, Shulman (1986) coined the term pedagogical content knowledge (PCK). According to Shulman, PCK "includes the most useful forms of representation of these ideas [the content to teach], the most powerful analogies, illustrations, examples, explanations, and demonstrations - in a word, the ways of representing and formulating the subject that make it comprehensible to others" (Shulman, 1987, p. 9). Moreover, PCK is a specialized teacher knowledge, an aspect of their professional knowledge that distinguishes a pedagogue (someone who can teach the content) from a content specialist (someone who knows the content). Further, PCK can distinguish a science teacher from other teachers in different content areas (Lee \& Luft, 2008).

PCK is important teacher knowledge, however, the nature of this knowledge is still in flux after plethora of research studies in last three decades (e.g., GessNewsome, 1998; Gess-Newsome, 2015; Grossman, 1989; Hashweh, 1987; Lee \& Luft, 2008; Loughran, Milroy, Berry, Gunstone, \& Mulhall, 2001; Magnusson, Krajacik, \& Borko, 1999; Mark, 1999; Park \& Oliver, 2008; Tamir, 1988). The literature reveals an ongoing debate on the structural clarification that mainly surrounds which knowledge components are included in PCK and how they interconnect (e.g., Hashweh, 2006; Lee \& Luft, 2006; Park \& Oliver, 2008). However, the view of PCK as experiential knowledge is shared by many researchers in the area of science education (e.g., Hashweh, 2006, Kind, 2015; Veal \& Makinster, 1999). According to Shulman (1987), teachers' knowledge is practical, develops over years of experience, and is about how they have accumulated "wisdom of practice" (Shulman, 1987). Gudmundsdottir (1991) noted the experiential nature of

(c) $\mathbf{2 0 2 0}$ by the authors; licensee Modestum. This article is an open access article distributed under the terms and conditions of the Creative Commons Attribution License (http://creativecommons.org/licenses/by/4.0/). 


\section{Contribution to the literature}

- The present study considers personal pedagogical content knowledge (pPCK) as an accumulation of experience of teaching a specific science topic, and teachers' voice as a representation of their experiences.

- A narrative inquiry approach is used to study experiences of teaching force and motion topics of four high school science teachers in Canada.

- Previous research has identified teaching experience as a deciding factor in shaping science PCK. However, this study expands the concept and definition of experience that influence development of science PCK. The findings point to the ways in which the participant teachers developed their pPCK related to force and motion influenced by their experience of teaching these topics, and not by overall teaching experience.

PCK. According to her, PCK is a "practical way of knowing" and is mostly "homemade" (p. 35). Fenstermacher asserts that PCK is no different from personal and personal practical knowledge (1994, p. 6). Besides the practical and experiential nature of PCK, Gudmundsdottir (1991, 1995, 2013) also noted the narrative nature of this type of knowledge. According to Gudmundsdottir (1991), “the study of teachers' narratives brings educators to the heart of pedagogical content knowledge" (p. 34). Hashweh (2006) expanded on the narrative nature of PCK by conceptualizing PCK as a collection of topic-specific pedagogical constructions (TPCs), which are smaller knowledge entities or units.

Despite acknowledging the experiential nature of PCK, researchers have not focused on the narrative nature of PCK. Exploring the narrative nature of PCK has become more important with the recent threefold vision of PCK proposed by Carlson and Daehler (2019) in the Refined Consensus Model (RCM) as a result of PCK Summit \#2, which view PCK as: (i) collective, (ii) enacted, and (iii) personal. The research on science PCK has focused on collective PCK by studying PCK of a group of teachers and reporting their PCK collectively (e.g., Loughran, Berry, \& Mulhall, 2006), and on enacted PCK by investigating the integration of various knowledge into PCK (e.g., Park \& Chen, 2012). However, the idea of personal PCK is still in infancy and needs to be explored.

This research investigates $\mathrm{pPCK}$ of science teachers while assuming that pPCK is a "practical way of knowing" and is mostly "homemade" (Gudmundsdottir, 1991, p. 35) and not different from the "personal and personal practical knowledge" (Fenstermacher 1994, p. 6). There had been a tradition of searching personal knowledge through studying teachers' narrative (Clandinin, 1986; Connelly $\mathcal{E}$ Clandinin, 1986; Elbaz, 1981, 1983). There is a need to study science teachers' pPCK through teachers' narrative, by interpreting their teaching experiences.

Recognizing the practical, experiential and narrative nature of PCK, the present research aims to study science teachers' experiences of engagement with a specific science curriculum through their narratives of teaching force and motion ideas to access their PCK. The following research questions guided the study:

1) How might teachers' descriptions of experience, organized as stories, reveal aspect of their pPCK of teaching science topics?

2) How might analysis of teachers' stories of teaching science topics describe the role of teachers' background and experience in shaping their $\mathrm{PPCK}$ ?

\section{THEORETICAL PERSPECTIVES AND THE CONCEPTUAL FRAMEWORK}

This research is underpinned by the practical, experiential, and narrative nature of PCK. Furthermore, a comparative analysis of RCM and a conceptual framework of topic-specific PCK guided a conceptualization of pPCK, which provided an analytical framework to organize and analyze data. The following sections present these underlying conceptions about pPCK as identified in the literature, and the conceptual framework developed to analyze teachers' narrative.

\section{The Practical and Experiential Nature of PCK}

Experiential knowledge is conceived as being located in human experience and practice. The teacher knowledge located in their practice and experience of teaching has been termed as practical knowledge, personal knowledge (Elbaz, 1981, 1983), personal practical knowledge (Clandinin, 1986; Connelly \& Clandinin, 1988), the wisdom of practice (Shulman, 1986) and professional knowledge. These are important knowledge types that teachers develop through practice. Researchers such as Elbaz (1981, 1983), Clandinin (1986), and Connelly and Clandinin (1988) have used innovative approaches to study teachers and teaching. In Shulman's (1987) view, teachers' knowledge is practical, develops over years of experience, and is about how they have accumulated "wisdom of practice" (Shulman, 1987). So, PCK is acquired and possessed by expert teachers (Veal \& Makinster, 1999) that they developed 
"on the job, but working with texts, subject matter and students in different contexts year after year" (Gudmundsdottir, 1991, p. 35).

\section{The Narrative and Value-laden Nature of PCK}

Gudmundsdottir worked with Shulman (1987) as a graduate student on his project Knowledge Growth in Teaching. She has written extensively about the narrative nature of PCK (Gudmundsdottir, 1991, 1995, 2013). According to Gudmundsdottir (1991), "the study of teachers' narratives brings educators to the heart of pedagogical content knowledge" (p. 34), and narratives are "packages of situated knowledge" (Jorden, 1989, as cited in Gudmundsdottir, 1991). Hashweh (2005), another of Shulman's graduate students, who conducted his research on PCK of teachers in the same Shulman's project, also highlighted the value-laden nature of PCK, and conceived PCK as a collection of topic-specific pedagogical constructions (TPCs), which are smaller knowledge entities or units. According to him, "a group or collection of [these] smaller knowledge entities" is called PCK (p. 27). Hashweh also believed that PCK is better understood as a collection of TPCs instead of a whole. Since each teacher develops TPCs as a result of the experience of teaching that topic over a long time, these small units of knowledge, TPCs, are situated in personal experience and values of the teachers and are context-dependent.

\section{The Approaches to Study Science Teachers PCK}

A review of literature on PCK shows that the dominant methodologies used to study science teachers' PCK include case studies (Lee \& Luft, 2008: Park \& Oliver, 2008: Ozden, 2016), interview research (van Driel, Verloop, \& de Vos, 1998), multi-methods approaches (Loughran et al., 2004; Nilsson, \& Karlsson, 2019; van Driel \& DeJong, 2001), and grounded theory approaches (de Jong \& van Driel, 1998; van Driel, Verloop, \& de Vos, 1998). Recently, the idea of developing tests that can evaluate science teachers' PCK has gained popularity. Some researchers have used these tests as data collection tools (Kirschner et al., 2016; Rosenkränzer et al., 2017; Schmelzing et al., 2013; Stasinakis \& Athanasiou, 2016) and quantitative data analysis techniques to study science teachers PCK. Interviews had been the most popular form of data tools used by many researchers (e.g., Henze, van Driel, \& Verloop, 2008; Drechsler \& van Driel, 2008: Ozden, 2016). Most of the interview studies used content analysis to reveal PCK components. A few studies used interviews to focus on teaching practice (e.g., Henze et al., 2008: Loughran et al., 2004, 2006). However, the use of interviews as a narrative data tool is not common, and narrative inquiry as a research methodology is missing in the research literature on science PCK. The only mention of the word narrative was found in the work of Loughran et al. $(2004,2006)$. Still, they did not call their research methodology "narrative inquiry," nor their analysis "narrative analysis." I choose to employ a narrative inquiry approach to study science teachers' pPCK related to force and motion ideas, which has been considered the most suitable approach for studying teachers' personal knowledge.

\section{The Conceptual Framework}

There had been efforts to develop a consensus around various notions of PCK through two PCK summits and three edited books. After introducing a Consensus Model (CM) in 2015, recently, the Refined Consensus Model (RCM) has been presented. The RCM is "centered around the practice of science teaching," and reveals complex layers of knowledge and experiences that shape and inform teachers' practice" (Carlson \& Daehler, 2019, p. 82). RCM identified three layers of PCK: collective PCK (cPCK), personal PCK (pPCK), and enacted PCK(ePCK). CPCK is defined as a "specialized professional knowledge held by multiple educators in a field." pPCK is described a "personalized professional knowledge" held by individual science teachers, and ePCK is viewed as a "unique subset of knowledge that a teacher draws on to engage in pedagogical reasoning during the planning of, teaching of, and reflecting on a lesson" (Carlson \& Daehler, 2019, p. 82).

Carlson and Daehler (2019) acknowledged the need to connect RCM to other models to define and make explicit various aspects of PCK. Similarly, Cooper (2019) suggested reconsidering existing PCK models. Here, I have considered my existing ideas about PCK, and performed a comparison between a topic-specific PCK Model and RCM, to make explicit the view of $\mathrm{PPCK}$ as it subsists in science teachers' experience or their description of experiences of teaching science. The intention was to "unpack what teachers are thinking about during the development and use of pPCK" Carlson and Daehler (2019, p. 84).

Based on a literature review of the research on science PCK, Author (2015) proposed a conceptual framework to depict topic-specific PCK of science teaching (see Figure 1). This conceptual framework includes nine topic-specific professional knowledge (TSPK) components shown as specific in Figure 1. These TSPK components emerged from individual teacher knowledge categories, called as teacher knowledge bases in RCM, as a result of the integration of each teacher knowledge base with the conceptual understanding involved in a science topic, which has emerged from the tenth teacher knowledge base. The ten teacher knowledge bases included in this conceptual framework has been identified by various researchers as features of PCK. To review, these are: (i) subject matter knowledge /content knowledge, (ii) knowledge of student learning, (iii) knowledge of instructional strategies, (iv) knowledge of curriculum, (v) knowledge of goals, (vi) knowledge of resources, (vii) knowledge of 


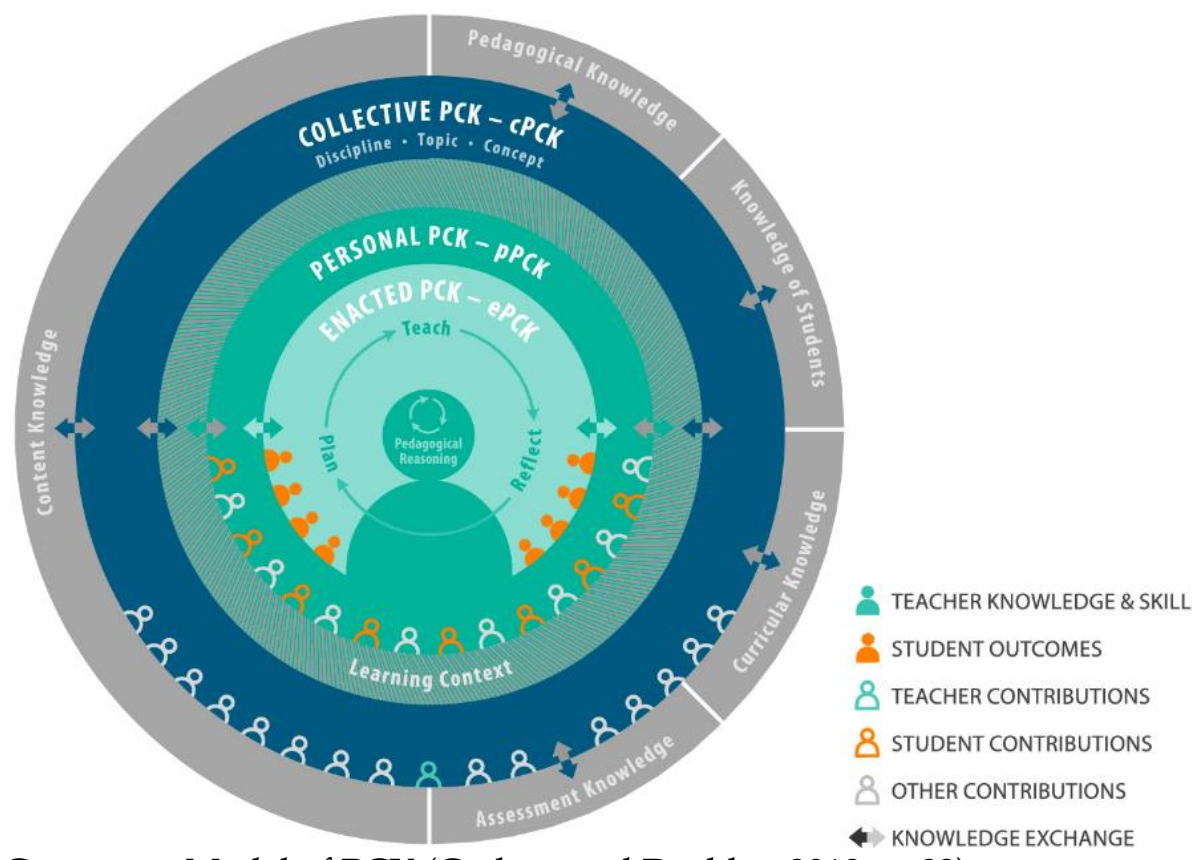

Figure 1. Refined Consensus Model of PCK (Carlson and Daehler, 2019, p. 82)

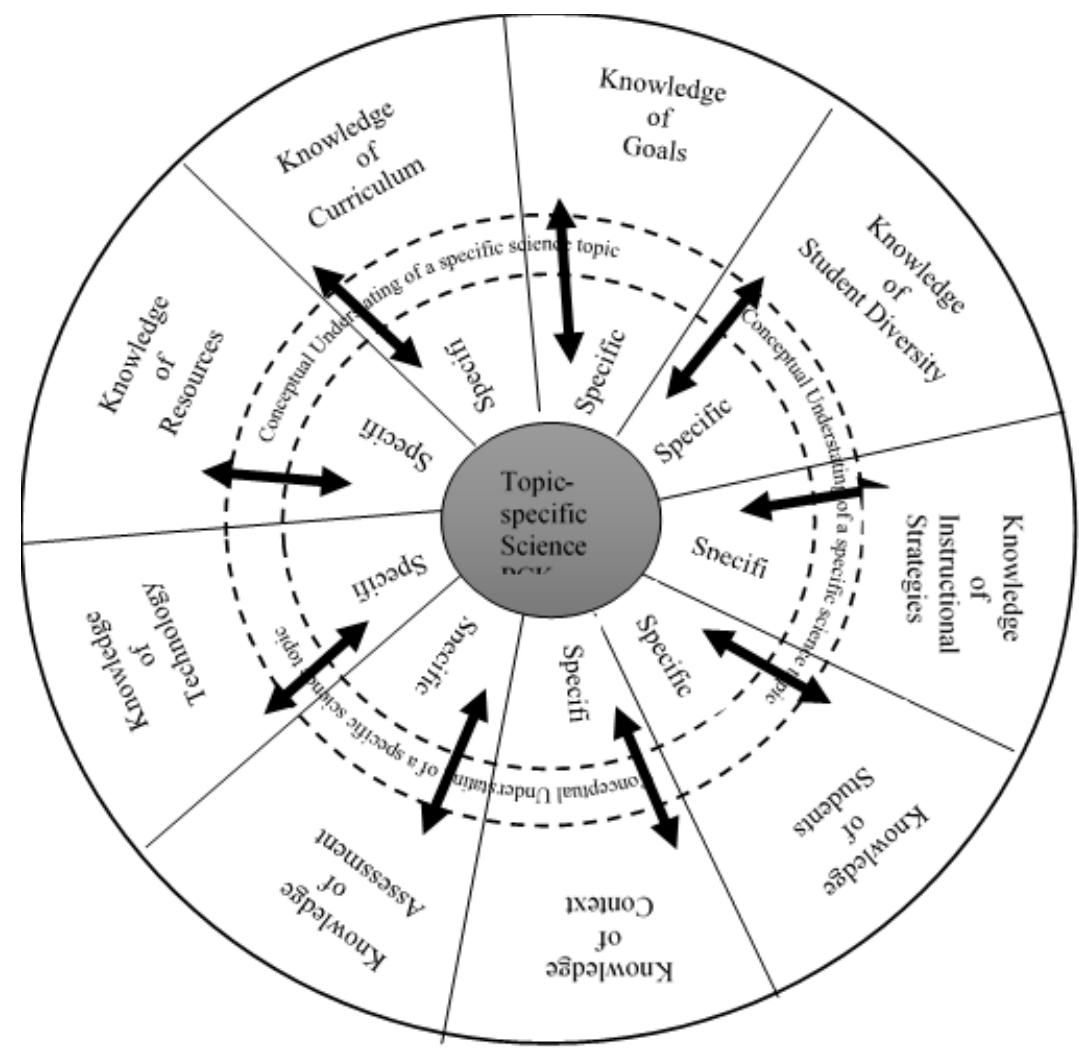

Figure 2. Conceptual Framework - Topic-specific Science PCK as presented in teachers narrative (Azam, 2015)

assessment, (viii) knowledge of teaching context. (ix) knowledge of technology, and (x) knowledge of student diversity. The last two knowledge bases have been suggested by the author (2015).

I further noted that the conceptual understanding of teachers, emerging from teacher knowledge base, subject matter knowledge, integrates with each one of the nine professional knowledge bases to develop nine topicspecific professional knowledge components comprising small bundles of narrative knowledge. After
Hashweh (2006), I called these small bundles of narrative knowledge as topic-specific pedagogical constructions (TSPC), and TSPCK was conceived as a collection of a number of these TSPC. Figure 2 presents this conceptual framework, which was used to organize teachers' professional knowledge of teaching force and motion topics held as small bundles of knowledge within teachers' narratives of teaching force and motion topics, and TSPCK was conceived as a collection of a number of these TSPC. 
Table 1. Participant Teachers' Professional Qualifications

\begin{tabular}{lll}
\hline Name & Education & Specialization \\
\hline \multirow{2}{*}{ Kevin } & BSc & $\begin{array}{l}\text { Biology as Major } \\
\text { Outdoor Environmental Education as Minor } \\
\text { Secondary science curriculum }\end{array}$ \\
\hline \multirow{2}{*}{ Jason } & BEd, Two-year after-degree & $\begin{array}{l}\text { Chemistry majors, Physics majors } \\
\text { Secondary science curriculum }\end{array}$ \\
& BEd, Two-year after-degree & Computational Physics \\
\hline \multirow{2}{*}{ Monica } & PhD and Post-Doctoral & Mathematics as Majors \\
& BSc & Secondary mathematics curriculum \\
& BhD & Education \\
\hline \multirow{2}{*}{ Dave } & BSc & Biology majors \\
& BA & Sociology majors \\
& BEd, Two-year after-degree & Secondary science curriculum
\end{tabular}

Table 2. Participant Teachers' Science Teaching Experience

\begin{tabular}{llll}
\hline Name & No of Year & Grade Level & Force \& Motion Topics \\
\hline Kevin & 8 years & Grade 7, 8, \& 9 science & 5-10 times \\
& & Grade 8 mathematics & \\
\hline Jason & 2 years & Grade 11, 12 & 5-10 times in high school, \\
& & Physics 20, Physics 30 & 15-20 times overall \\
\hline Monica & 14 years & Grade 7, 8, \& 9 Science & 5-10 times \\
& & Grade 7 Mathematics & 5-10 times \\
\hline Dave & 15 years & Science 10, Bio 20 \& Bio 30 &
\end{tabular}

This conceptual framework helped in analyzing science teachers' narratives of teaching force and motion, and provided structure to their stories of teaching force and motion-documented pPCK of science teachers.

This conceptual framework was designed before RCM was introduced, however, this appears to fit within RCM to provide a further elaboration of pPCK. RCM considered pPCK as one of the three layers to represent PCK and described it as a "personalized professional knowledge" held by individual science teachers. However, RCM did not further illustrate pPCK, and left it to the researchers to search PPCK through research on science teaching. I think the conceptual framework described above fits well within the RCM, and can be considered as an illustration of personal topic-specific PCK.

\section{METHODOLOGY}

To study secondary school science teachers' experiences of engaging with a specific science curriculum, I chose a narrative inquiry approach as the methodology for this research study. Narrative Inquiry is an appropriate way to study experiences (Clandinin \& Connelly, 1986) that "allows for [the] systematic study of personal experience and meaning" (Riessman, 2001, p. 45). Based on the type of data and analysis used, Polkinghorne (1995) notes two types of narrative inquiries: (i) Narrative Analysis and (ii) Analysis of Narrative. The first type of narrative inquiry "gathers events and happenings as its data," and then "uses narrative analytic processes, called narrative analysis, to produce explanatory stories" (p. 1). Use of narrative analysis allowed reconstruction and reorganization of the knowledge of the professional practice of participant teachers to portray their pPCK. The following sections describe the processes undertaken for this inquiry, which include an introduction to the research participants, the data sources used, and the procedures I followed to collect and analyze the data.

\section{The Research Participants}

The research study focused on four secondary school science teachers Kevin, Jason, Monica, and Dave (Pseudonyms). Initially, seven high school science teachers were conveniently available; however, these four teachers were willing to share their stories in details and had diverse backgrounds. Monica and Kevin are junior high school teachers, while Dave and Jason are senior high school science teachers. Jason has a background and exceptionally diverse experiences in teaching physics. Monica and Dave have backgrounds in biology and have little interest in physics teaching, though they teach physics topics as part of the science curriculum. Kevin has a background in biology and chemistry but is interested in physics teaching. All four participant science teachers hold both BSc and BEd degrees, the required qualification to become a secondary science teacher in Alberta, Canada. Monica and Jason have also both completed their post-graduate degrees. Table 1 presents participant teachers' qualifications, and Table 2 outlines their teaching experiences.

\section{The Selection of Topics as a Context for This Study}

I selected topics related to force and motion as a context for this study. This was an ideal topic area as it 
recurs across several grades in the Province of Alberta Secondary Science Program of Studies. In the junior high science curriculum, these topics are discussed in Grade Seven in the unit Structures and Forces, and again in the Grade Eight unit Mechanical Systems. Grade 10 Science has a discussion on force and motion in the unit Energy Flow in Technological Systems, and a detailed discussion of force and motion is also found in Physics 20.

\section{Data Collection}

The data for this research study are the interview transcripts of conversations with the participant teachers in which they describe their work as planners and enactors of the science curriculum. I used a tentative list of topics related to force and motion and an interview protocol in a suitable way to invite the participant science teachers' stories about the events and happenings related to these topics. Teachers' stories provided a view into the complexities of the pedagogical decisions teachers made while enacting a science curriculum related to these topics, both in their planning and teaching. The numerous short stories of teaching collected from each participant science teacher, audiotaped and transcribed, served as data sources across various topics regarding teaching about force and motion. These multiple data sources were used later to triangulate the data.

\section{Data Analysis}

\section{Developing stories of teaching}

The data were analyzed and organized to produce coherent explanatory stories by using the "narrative configuration", the process by which happenings are drawn together and integrated into a temporally organized whole called a "narrative" (Polkinghorne, 1995) or "story" (Elbaz, 1991). The intention was to produce stories that present information in a logical way that retains the wholeness of each individual's description of experience and generates insights about their pPCK. To develop the accounts of the participant's teaching. I used a two-step process. First step involved developing topic-stories. I developed four to twelve topicstories for each participant, depending on the topics they selected and discussed. To assist the process of narrative configuration for developing a topic-story, I carefully reviewed the transcript of the interview conversation to identify narrative fragments - small pieces of narrative data about teaching force and motion. I reviewed the transcript at least three times to ensure that all relevant narrative fragments were identified. Then. I weaved together these relevant narrative fragments to configure a topic-story (See Appendix A for an example of the topic story). Second step involved developing stories of teaching. To assist the process of developing a consolidated story of teaching force and motion topics for each participant, I triangulated the data collected about teaching multiple force and motion topics by engaging in an analysis, which I call "inter-story triangulation analysis." I weaved the narrative fragments representing a particular PCK component in topic stories of a participant teacher and configured a section in their story of teaching force and motion representing that particular component. I repeated the process for all ten components. Figure 3 shows the process of inter-story triangulation.

Using Veal and Makinster's (1999) general taxonomy of PCK, I considered the continuum of science PCK, which consists of four levels that represent the topicspecificity of PCK components within stories of teaching. 1 used the PCK continuum, the four-level criteria, to analyze teachers' ideas in the ten knowledge bases. Level one was assigned to an idea that a teacher shared about teaching force and motion topics, but did not make any reference to the force and motion topics. Level two was assigned to an idea with mention of a topic related to force and motion. Level three was assigned to an idea with mention of a concept related to force and motion. Level four was assigned to an idea with a mention of conceptual understanding of topics related to force and motion. Using the above TSPCK framework, I created visuals for each teacher's pPCK, emphasizing the differences or similarities strengthening the role of teacher background and experience.

\section{Achieving Trustworthiness}

I used member checks to ensure that the meanings correctly represent experiences as the participants described them (Lincoln and Guba, 1985). I shared the drafts of the stories with the participants and asked for their input, comments, or suggestions to modify or improve the accounts. This process ensured that the teachers' narrative accounts were credibly represented from the participants' perspectives and were not just the perceptions of the researcher.

\section{FINDINGS}

Four stories of teaching developed as a result of narrative analysis reveal participant science teachers' conceptual understanding of the content (force and motion ideas), and a unique understanding of how to teach this content to secondary school students-their $p P C K$. First, I present narrative fragments, topic-specific pedagogical constructions (TSPC) of knowledge situated in participant science teachers' experience of planning and teaching force and motion ideas in the following ten sections. These knowledge fragments represent aspects of their pPCK revealed within stories of the teaching of these four science teachers. Then, I present an analysis of the four stories of teaching to portray the level of topic-specificity 


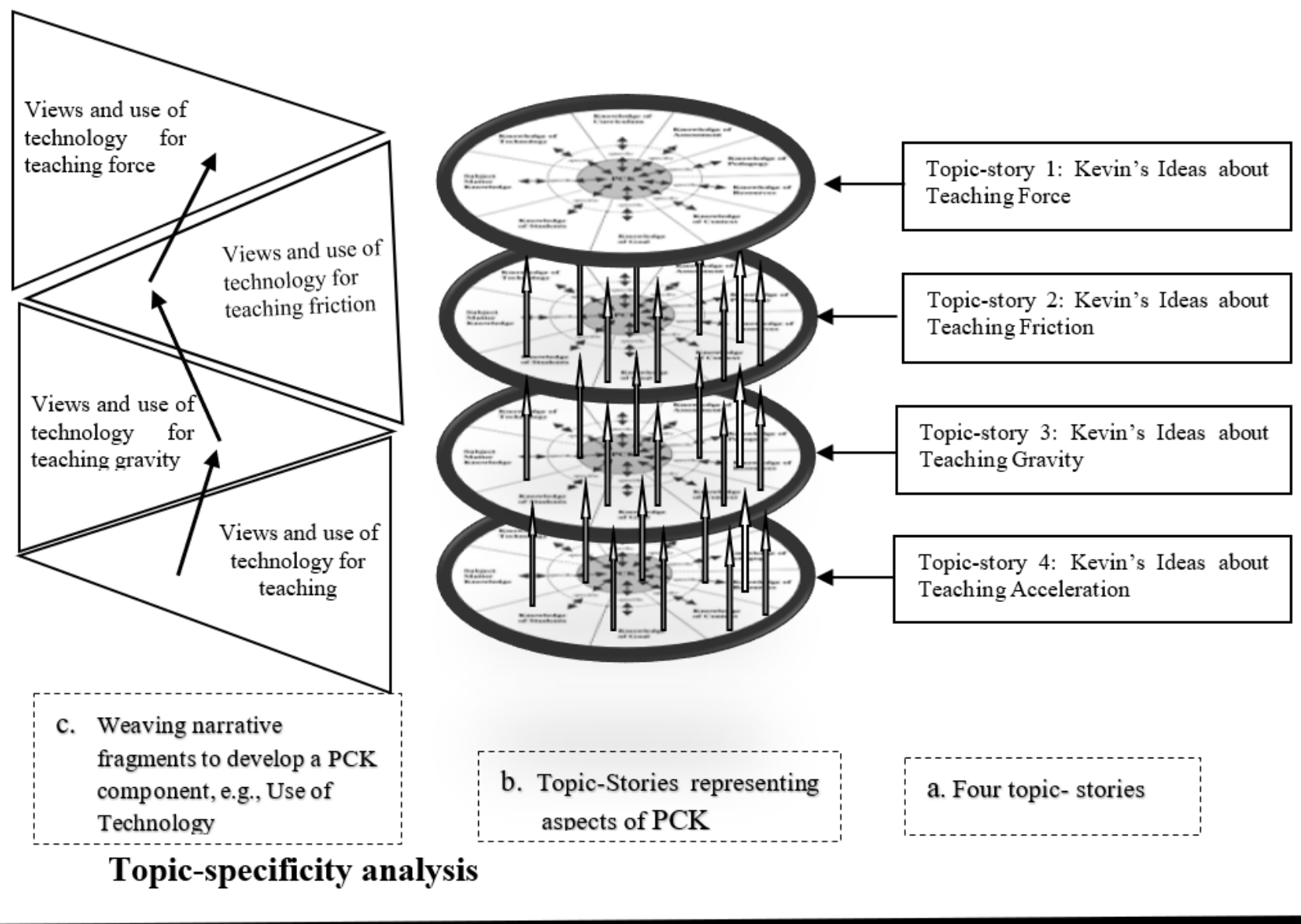

Figure 3. Process of analyzing data (triangulation) for developing Kevin's story teaching

of these pPCK aspects to present topic-specific nature of pPCK.

\section{Aspects of Science Teachers' pPCK}

\section{Teachers' views and understanding of force and motion concepts}

Teachers develop a unique understanding of science topics, emerging from their subject matter knowledge and result of their distinctive experiences of teaching these topics over time. This exclusive understanding of science content is the most important aspect of a teacher's pPCK. In this research, each teacher revealed a unique understanding of force and motion concepts, usually shaped by the specific science curriculum they teach. Here I present some excerpts from stories of their teaching:

Describing, what it means to understand force - the underlying ideas or concepts he wants his students to understand, Kevin said: "Force is a push or pull" and students should be able to demonstrate it, which is achieved when students can "push an object and say, 'I just applied a force on the pen and made it move." Students should be able to measure force using appropriate devices and standard units. Therefore, he planned his lesson in a way that his "[students] could get. . . some understanding of measuring a force . . . [which includes] not necessarily going to a formula and doing the calculation, but even if they could see if "I apply a big force to a small object I can send it flying." In addition, Kevin noted that his students should be able to understand the relationship between mass and force, and he let students do an experiment with objects of different mass - by applying different amounts of force on each of these objects. Using this experiment he said that they can learn for themselves the connection between mass and force, they can say, "If I apply a big force I am pushing hard or pulling hard, and it moves farther," and by doing so, "they get the idea of distance." (Kevin's views and understanding of the concept of force)

Jason acknowledged that the concept of force as push or pull is a useful concept that cannot be discarded. However, Jason stated that students need to be told at a particular stage and grade level that there is something more than push or pull to force. Jason also criticized the idea of treating force as an object or a thing and trying to find what this thing is. He thinks it is not important for students to know "what a force is" [in terms of push or pull] and thus is against the view of spending too much time on trying to understand what a force is. Jason said it is better to discuss force as a push or pull in the context of an interaction between two things. He conveyed that he rather prefers to define force operationally - what a 
force does, and he has a specific way of doing so. (Jason's views and understanding of the concept of force).

\section{Teachers' understanding of students' alternative ideas}

For science teachers understanding their students' learning difficulties and specific learning needs, and hence being able to help them understand specific science topics is an important aspect of their pPCK. For example, Jason, Kevin and Monica noted that his students' alternative ideas about force and motion are rooted in the everyday use of the word. For example, Jason shared: One of the things that I struggle with . . . [is] the word "force". . [ [It] inform[s] so many concepts that are used colloquially, thousand times more often than they are used in the physics classroom, and force is one of them. So, these students come in with an idea of what force is, [and] what [force] is not . . . informed by their prior education or sometimes ... is informed by the fact that ... the last night they heard that somebody [in] a reality show that they were watching [said,] "it is a real force of nature" or something like that." (Jason's understanding of students' alternative ideas). Similarly, Kevin shared his experience that he has a hard time teaching about force because his students make unnecessary and wrong connections between force as a science concept and the ideas of force in the Star Wars films, where it is a mystical power. The movies' presentation of force has created a great hindrance to his students' scientific learning about force.

\section{Teachers' repertoire of instructional strategies}

One aspect of a science teacher's pPCK is knowledge of pedagogy itself, which means knowing contentspecific instructional strategies that help students develop a conceptual understanding of force and motion topics. A review and analysis of the teaching strategies that teachers shared during our conversations reveal their understanding of the instructional strategies that they follow during their teaching of the topics related to force and motion. For example, Dave says that the topics of distance and displacement "come with [the topics of] scalars and vectors." He explained how he teaches all the concepts together, so that the students can develop an understanding of these topics in the context of realworld scenarios. He told me about how he presents a scenario to his students: "[Imagine] you have covered 100 kilometers, 50 kilometers north, and 50 kilometers east. What is the difference between the total distance . . . [and] the total displacement from where you came?" He stated that he lets his students explore these ideas, then has them "calculate [distance and displacement], and show [the results] on graphs, and understand what is happening about those concepts."

\section{Teachers' views, knowledge, and use of teaching resources}

During our conversations, all four teachers mentioned using various teaching resources that they find effective to support classroom activities for the force and motion unit. For example, Kevin shared his experience of having seen an amazing set of manipulatives:

They were like a bicycle but just pedals and the crank part [and] they were three of them ... One [of them] was . . . well maintained [with ball bearings, and] lubricated, the other one [had] ball bearings ... but was not lubricated, and [the third] was without ball bearing [perhaps].

Kevin said that this is a very good resource for students to "turn the cranks and ... felt the temperatures of it" to understand the "idea that the lubricated one is the coolest and [thus] is the most efficient ... [because] there is less friction." Kevin said that he believed that these manipulatives were specially manufactured for teaching grade eight science for exploring relationships between friction and efficiency. Similarly, Jason uses the wonderful worksheet idea that he came across in Court's (1999) journal article in Physics Teacher. This article contains thoughtfully designed free body diagram problems, which Jason thinks can help students develop a systematic understanding of free body diagrams and help them in solving numerical problems, so he uses it regularly in his high school classroom.

\section{Teachers' views, knowledge, and use of technology}

All four teachers have used different technologies to support their students' understating of force and motion ideas. During our conversations, they revealed these technologies and how they use these to improve their teaching as well as their students' learning. For example, Monica has used an online simulation in her science class to help her students better understand forces and structures. In her words,

There is [a website] Building Big [http://www.pbs.org/wgbh/buildingbig, which is] ... on different types of forces. ... [It] talks about the different types of materials, it talks about loads, it talks about shapes, and all kinds of things that you need to know when you are designing something.

Similarly, Kevin shared an example of an "airplane simulators where [students] can momentarily defy gravity." Then, he talked about the Bill Nye the Science Guy video series, which he uses quite a bit. Kevin brought out an example of one of these videos that he has used for teaching about friction, and said, "It is a video where he 
spills ... marbles and walks on the marbles ... to cross it." Also, Kevin said that he has used the website www.explorelearning.com to help his students understand frictional forces. He said that this website has "gizmos that you can use to present real-world situations. . . . There is one in there...that is using . . . an inclined plane . . . [where you can] change the surface of the inclined plane and measure friction."

\section{Teachers' views and understanding of the science curriculum}

Understanding science curriculum has been considered an important aspect of science teachers' PCK, which includes understanding (a) specific curricular programs and materials that are relevant to teaching a specific science topic and (b) mandated curriculum objectives. This aspect of teachers' pPCK focuses on sequencing different related concepts to help students better understand a science topic. Jason considered the science program of study a guide to plan for teaching science, which he identifies his legal responsibility as a high school science teacher. However, he also indicated that the content selection and its organization is personal and rooted in the learning needs of the students. This needs to be improved constantly, based on the teacher's reflections on teaching. Regarding content selection, Jason asserted that he changes the sequence of presenting topics in the textbook and follows the sequence that helps his students understand these topics, based on his experiences of working with these students. Based on his reflections, Jason has modified the content organization of force and motion ideas. Similarly, Monica considered the appropriate age and grade level to introduce the topic of force, which she thinks is an abstract concept, and therefore it is included at the junior high school level because students are able to understand "some of these abstract concepts" because of their "level of understanding . . . and readiness." She also pointed out the importance of including the history of science topics within the curriculum. In her words:

One of the problems with ... the curriculum is, it is [so full of] ... facts and figures, and laws and theories that sometimes we forget the human component, the people and history behind all of these discoveries. So, that is something missing in our curriculum for sure. ... We never get a chance to get into the historical aspect of how this idea came about ... I mean, we mention Newton, but do we ever get into any depth about him . . . or James Joule or . . I mean, other than recognizing that these people came up with some of these concepts. I think that is a problem with our curriculum.

\section{Teachers' goals of teaching force and motion}

Each curriculum is tied into specific goals. However, influenced by their own beliefs and values, teachers may have some other, personal goals to achieve when planning and teaching these topics, which becomes a part of their pCPK. For example, Kevin said that if students understand about force and motion, they can learn about the safety issues involved in driving a car. Kevin conveyed that one of the goals of teaching force and motion ideas at this level is to help the students understand forces involved when riding a bike or playing hockey: "Before they drive, they bike, and they play hockey; understanding what those forces are is important too." In addition, Kevin indicated, "If [students] understand the idea of force [a]s a push or pull that helps them understand ... for example, Newton's laws' of motion [and] ... definitely [it is] something that is important before they go to the high school and take physics." Kevin further explained that if students "have that basic understanding of what the physical laws are, and the laws of motion, they can be successful in high school. Kevin believes that it is important for grade eight students to understand the concepts of friction, because "that has a huge impact on their understanding of efficiency ... and the [idea of] transfer of heat." Similarly, Monica stated that it is important for them to understand "how friction is important in real life." She added that teaching about gravity is important to grade seven and eight students which is not included in mandated curriculum "because they are going to be talking about space science in grade nine, so they need to have some kind of idea [of] what gravity is."

\section{Teachers' views and understanding of considering various teaching contexts}

The knowledge of contextual factors, such as urban or rural school settings and science curricula, is relevant to a science teacher's life, and it is responsible for reshaping their $\mathrm{pPCK}$. The way science teachers engage their knowledge of various contexts with specific science topics transforms their knowledge, so that it may become part of their pPCK. For example, when asked how he will teach about force if he does not have any manipulatives or technology to use in the classroom, Kevin replied, "I can teach force in the middle of the basketball [court] by just using the ball." He used this example, perhaps because he is a basketball coach. However, when talking about friction, he indicated that "in an urban school as compared to a rural school . .., there would be a difference" because Kevin believes that rural kids have some prior knowledge of efficiency and simple machines. Hence, he assumed that his teaching in a rural context would be different from an urban context for this topic. Similarly, some of the variations occurred for Monica. She explained that from "year to year, depending on what type of students I have ... I do not teach the same way. . . I try different activities, [and do 
these] in different ways, depending on the [group of] students." In context of new technologies, She explained that she has a SMART board now in class, and "[does] a lot of virtual labs online."

\section{Teachers' views and understanding of assessing science learning}

Effective science teachers need to know and apply various assessment techniques to make sure that their students have developed the intended understanding of the concepts and ideas taught to them. Some specific assessment techniques have also been developed and used to get to know the prior knowledge of the students, especially targeting their alternative frameworks for the ideas under study. During our conversations, participant teachers identified diverse techniques that they used to assess their students' understanding of topics related to force and motion, an important aspect of their pPCK. For example, describing the assessment strategies he uses, Dave responded: "It could be anything, from putting up [examples] on the SMART board, [and asking] which one is the distance and which one is the displacement? Just talking with the students [about ideas] ... from their lab investigations. ... and then follow up with the formula part of the lab, [and] having a quiz at some point." Dave also affirmed, "There will be a unit exam" at the end of each unit. When asked about which questions will appear on these unit exams, he said that a question about distance and displacement would always be there and on "analyzing the graphs."

Similarly, Jason stated that he had used specially designed multiple-choice questions to assess preconceived ideas of his students and to check the conceptual understanding of the students about force, with the Force Concept Inventory (FCI). Similarly, he uses appropriate questions in the context of Predict Observe - Explain (POE) activities [e.g., demonstration with a marble moving inside a tape] to help his students predict thoughtfully, observe carefully, and engage in discussion in order to understand the scientific explanation of the phenomenon under study.

\section{Teachers' views and understanding of addressing student diversity}

Many science teachers work with students from various ethnic, linguistic and cultural backgrounds, including new immigrants. For many students in today's classroom, English is a second language. During planning and teaching, science teachers should be able to identify the issues and provide accommodations to diverse students in their classrooms, which may result in developing their pPCK. For example, to include students from various cultural and ethnic backgrounds while teaching about structures, Monica tries to "incorporate . .. different types of structures ... globally." She said, "I push them to ... research something in Dubai and go and research something in Turkey, or [something] in Asia, or [something] in China." By using this approach, Monica stated that she wants her students "to recognize that these famous buildings are not just in Europe and Western society, but we have famous structures all over the world, going back to 1000 BC." I think this approach used by Monica is a multicultural approach to teaching science.

Similarly, Dave confirmed that he purposely uses graphs for teaching topics related to force and motion, to help ESL students' learning. He said, “What I love about graphs is, it does not matter how strong your language skills are, it's a tool that demonstrates" learning of ESL and other students.

\section{Topic-specificity of pPCK Components}

Further analysis of each of the above ten knowledge components, by placing them on the four-level PCK continuum mentioned above, revealed the breadth and depth of these knowledge components. The breadth was considered by the number of PCK elements-the TSPCs shared by the teacher, and the depth was considered by the level of topic-specificity. Table 3 shows the overall score of pPCK components and topic-specificity involved for four teachers.

Jason, a specialist high school physics teacher, shared total 65 pedagogical constructions, out of which 36 lie at the highest (fourth) level of topic-specificity, 12 lie at the third level, six at the second level, while 11 at the lowest (first) level. Monica, a junior high school teacher, trained as a mathematics teacher, shared a total 45 pedagogical constructions, out of which 14 lie at the highest (fourth) level, 18 lie at the third level, eight at the second level and five at the lowest (first) level. Kevin, a junior high school science teacher, shared a total of 43 pedagogical constructions, out of which 13 lie at the highest (fourth) level, 21 at the third level, seven at the second level, and nine at the first (lowest) level. Table 3 shows details of the pedagogical constructions within ten PCK knowledge aspects, as well as their breadth and depth.

Most of the pedagogical constructions were identified within three knowledge categories, content knowledge understanding, knowledge of students alternative ideas, and knowledge of instructional strategies (39 out of 65 for Jason, 25 out of 45 for Monica, 21 out of 43 for Kevin, and 13 out of 40 for Dave). Similarly, these three components of pPCK are more topic-specific in nature (level $3 \& 4$ ), while others are less topic-specific, where the level of topic specificity suggests a lack of integration between pedagogy and the science content - force and motion ideas, in this case. On the other hand, the specific nature of a pPCK component proposes that the science content is integrated well with the pedagogy to make it comprehensible for students, and is transformed into a distinct combination of content and pedagogy. This analysis considered the in-between 
Table 3. Overall Score of PCK Components/Elements and Topic Specificity Involved

\begin{tabular}{|c|c|c|c|c|c|c|c|c|c|c|c|c|c|c|c|c|c|c|c|c|}
\hline \multirow[t]{2}{*}{ pPCK Components } & \multicolumn{5}{|c|}{$\begin{array}{l}\text { Jason's pPCK } \\
\text { Elements \& Levels }\end{array}$} & \multicolumn{5}{|c|}{$\begin{array}{l}\text { Monica's pPCK } \\
\text { Elements \& Levels }\end{array}$} & \multicolumn{5}{|c|}{$\begin{array}{c}\text { Kevin's pPCK } \\
\text { Elements \& Levels }\end{array}$} & \multicolumn{5}{|c|}{$\begin{array}{c}\text { Dave's pPCK } \\
\text { Elements \& Levels }\end{array}$} \\
\hline & $\mathrm{T}$ & $\mathrm{L} 1$ & $\mathrm{~L} 2$ & L 3 & $\mathrm{~L} 4$ & $\mathrm{~T}$ & $\mathrm{~L} 1$ & $\mathrm{~L} 2$ & L 3 & $\mathrm{~L} 4$ & $\mathrm{~T}$ & L 1 & L 2 & L 3 & $\mathrm{~L} 4$ & $\mathrm{~T}$ & L 1 & L 2 & L3 & $\mathrm{L} 4$ \\
\hline 1 Views and understanding of concepts & 13 & 0 & 0 & 3 & 11 & 10 & 0 & 0 & 3 & 7 & 4 & 0 & 0 & 2 & 4 & 4 & 1 & 0 & 2 & 1 \\
\hline $\begin{array}{l}2 \text { Views and understanding of students' } \\
\text { alternative ideas }\end{array}$ & 10 & 1 & 1 & 2 & 6 & 7 & 0 & 2 & 3 & 2 & 4 & 0 & 0 & 4 & 1 & 2 & 0 & 1 & & 1 \\
\hline 3 Repertoire of instructional strategies & 16 & 0 & 0 & 2 & 12 & 8 & 0 & 1 & 3 & 4 & 13 & 3 & 2 & 7 & 4 & 7 & 0 & 0 & 2 & 5 \\
\hline $\begin{array}{l}4 \text { Views, knowledge and use of teaching } \\
\text { resources }\end{array}$ & 4 & 1 & 0 & 3 & 1 & 3 & 1 & 0 & 2 & 0 & 4 & 2 & 3 & 1 & 0 & 3 & 2 & 1 & 0 & 0 \\
\hline 5 Views, knowledge and use of technology & 5 & 1 & 3 & 1 & 0 & 2 & 0 & 0 & 2 & 0 & 5 & 1 & 0 & 4 & 0 & 5 & 3 & 0 & 2 & 0 \\
\hline 6 Views and understanding of science curriculum & 5 & 2 & 0 & 0 & 3 & 3 & 0 & 1 & 2 & 0 & 2 & 1 & 0 & & 1 & 3 & 2 & 1 & 0 & 0 \\
\hline 7 Views and understanding of goals of teaching & 3 & 1 & 1 & 0 & 1 & 3 & 0 & 1 & 1 & 1 & 1 & 0 & 0 & 1 & 1 & 1 & 1 & 0 & 0 & 0 \\
\hline 8 Views and understanding of teaching context & 1 & 1 & 0 & 0 & 0 & 4 & 3 & 1 & 0 & 0 & 1 & 0 & 0 & 1 & 1 & 2 & 2 & 0 & 0 & 0 \\
\hline 9 Views and understanding of assessment & 4 & 2 & 0 & 1 & 1 & 2 & & 1 & 1 & 0 & 5 & 2 & 1 & 0 & 0 & 8 & 3 & 2 & 1 & 2 \\
\hline 10 Views and understanding of student diversity & 4 & 2 & 1 & 0 & 1 & 3 & 1 & 1 & 1 & 0 & 3 & 0 & 1 & 1 & 1 & 5 & 3 & 0 & 0 & 2 \\
\hline Overall pPCK & 65 & 11 & 6 & 12 & 36 & 45 & 5 & 8 & 18 & 14 & 43 & 9 & 7 & 21 & 13 & 40 & 17 & 5 & 7 & 11 \\
\hline
\end{tabular}

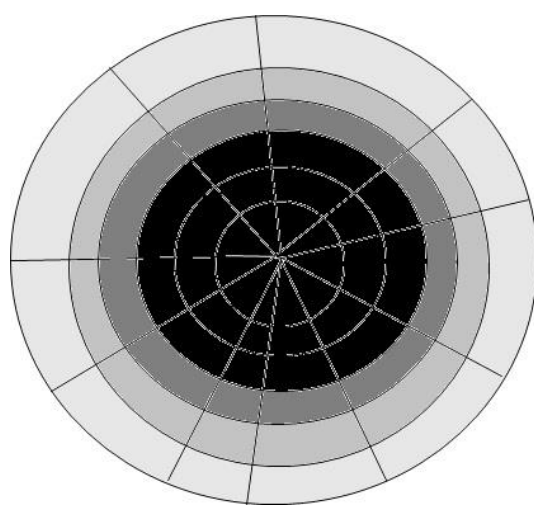

(a)

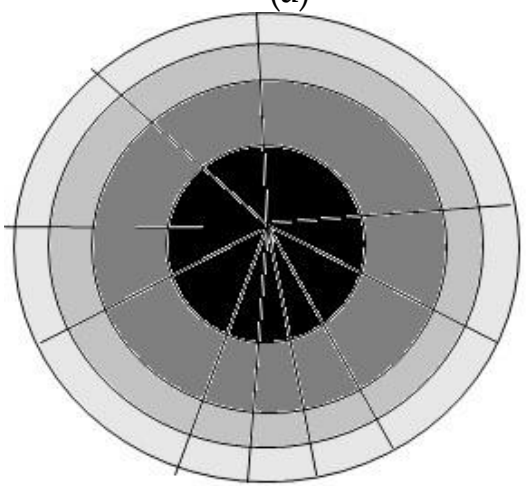

(c)

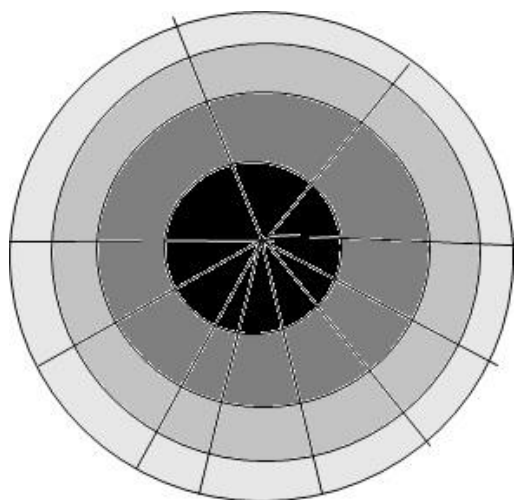

(b)

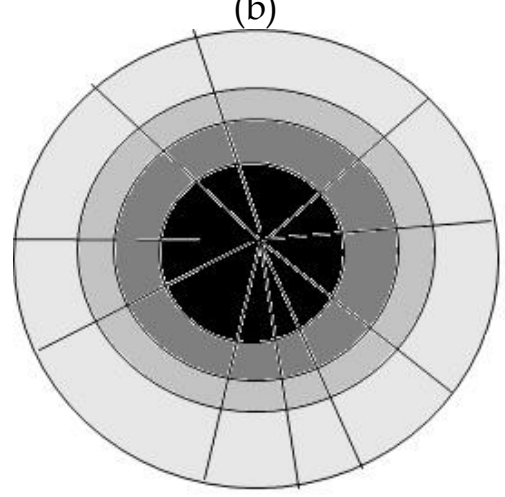

(d)

Figure 3. a) Jason's overall pPCK; b) Monica's overall pPCK; c) Kevin's overall pPCK; d) Dave's overall pPCK

situations where, within a pPCK component, the specific science content (force and motion ideas) is still in the process of integration or somewhat integrated with the pedagogy.

Figures 3a-3d depict illustrations of overall pPCK of the four science teachers, where size (diameter) of the circle shows the overall breadth and dark section at the center of the circle shows the overall depth of the pPCK of each teacher. A comparative analysis of these illustrations reveals fascinating similarities and differences apparently grounded in the individual teacher's subject area background and their specific teaching experiences. Jason who is a specialist physics teacher shows supreme pPCK regarding breadth as well as depth. Both Monica and Kevin, who are junior high school science teachers, present similar pPCK profiles; the depth of their pPCK lies at fourth and the third level and breadth is almost the same. Dave, a specialist biology teacher, presents pPCK that is lowest in depth (topic-specificity) while breadth is close to that of Monica and Jason.

\section{DISCUSSION}

I designed a narrative inquiry into the pPCK of four participant science teachers and collected narrative data by engaging them in conversations about conceptualizing and teaching force and motion ideas. Using narrative analysis technique, I organized teachers' descriptions of their experiences in the form of stories that revealed aspects of their pPCK. An analysis of stories of teaching force and motion revealed influences of teachers' backgrounds and experiences on shaping 
their pPCK. In the following sections, findings are discussed to highlight how this research study contributed to the literature on science teacher's pPCK.

\section{Narrative Inquiry Approach to study pPCK}

As described above, narrative inquiry is somewhat ignored in research on science teachers' PCK. This research is an effort to bring attention to the importance of this methodology, particularly when studying pPCK, following the tradition of approaching personal and personal practical knowledge of teaching science (Clandinin \& Connelly, 1986; Elbaz, 1991). This narrative inquiry borrowed ideas from Polkinghorne (1995) to distinguish between the process of storying (narrative analysis) and analyzing stories (analysis of narrative). The narrative of analysis technique is common, and similar to the inductive coding process, there is no clear procedures for narrative analysis available in the literature. This narrative inquiry has deviced a step-bystep procedure for developing stories of teaching science topics, and offer this procedure to the science education researcher community to authenticate and expand. I used this procedure to develop a narrative configuration for each participant teacher to represent their pPCK that I call "stories of teaching force and motion." Each story revealed a significant part of a teacher's journey of science teaching, but the journey itself will continue. As the journey never stops, the story never ends. However, these stories captured experiences of teaching force and motion that expose their pPCK related to teaching force and motion topics.

\section{Topic-specific pPCK}

This study used force and motion topics as context to study pPCK of science teachers. Only a handful research studies on science teachers' PCK has focused on force and motion topics (e.g., Alonzo \& Kim, 2015; Loughran et al., 2006), which are considered difficult for learning and teaching (Driver et al., 1994; Halloun \& Hestenes, 1985). Loughran et al. (2006) studied in detail PCK of a group of science teachers related to force and motion topics and presented their PCK in the form of CoRe (Content Representations) and Pap-eRs (Pedagogical and Professional-experience Repertoires). The CoRe and $\mathrm{PaP}-\mathrm{eRs}$ are based on collective ideas of a group of expert science teachers, which within the RCM model of PCK is considered as collective PCK (cPCK). Similarly, Alonzo and Kim (2015) used an innovative technique of videobased interviews and focused on practice-based aspects of PCK, which, according to RCM of PCK may be considered enacted PCK (ePCK). This narrative inquiry focused on stories of individual teachers to explore their pPCK of teaching force and motion topics. This research further strengthens the idea that PCK is a topic-specific knowledge, whether in the form of personal, enacted, or collective PCK.

\section{Explicit and Implicit pPCK}

Previously, others have discussed PCK as tacit knowledge - not transferable, and implicit knowledgenot easy to articulate (Lee \& Luft, 2008; Loughran et al., 2006). However, this study revealed that science teachers may, in fact, be able to articulate some or all the components of their pPCK as explicit knowledge. To be part of their explicit pPCK, science teachers need to be able to provide their reasoning for using a particular approach to teach a science topic in a specific pedagogical situation. For example, a particular teaching strategy used by a science teacher becomes part of their explicit pPCK only when he or she is able to provide a description and their reasons for using this strategy to develop students' conceptual understanding of the topic. I call this explicit $p P C K$, something that science teachers can describe and articulate with clear reasoning. At the same time, this study corroborates the previous findings noted above, in that it supports the view that science teachers may still have some knowledge components of PCK, even though they did not necessarily provide their reasoning at the time of the interview. The reasons might include a lack of clarity in the questions asked, the way questions were phrased, and the time available for discussion. Therefore, they may have pPCK that still needs to be explored. This is what I call implicit $p P C K$.

\section{Role of Science Curriculum in Shaping pPCK}

My analysis of participant science teachers' stories of teaching force and motion show that their pPCK is shaped largely by the science curriculum and the specific grade levels they teach. That my research participants were from various grade levels played a significant role in revealing this aspect of their pPCK. For example, Jason teaches at the high school level and Monica primarily at the junior high level. Therefore, the way they approach the content must necessarily be different, given the content requirement, and learning capacity and stages of their students.

Jason has taught force and motion topics in the context of the Alberta Program of Studies, Physics 20 and post-secondary courses in introductory physics, both embedded in the area of basic mechanics, covering force and motion ideas. Both courses outline largely identified examples, activities, and resources for force and motion ideas. Monica's current experiences of teaching force and motion topics are in grade seven, but she has some experience of teaching grade eight and nine science. She articulated ideas about force mainly in the context of structures, which appeared to be influenced by the grade seven unit, Structures and Forces, in the Alberta Science Program of Studies. However, while talking about friction, she brought up examples from the grade eight unit, Mechanical Systems. Similarly, while talking about gravity she raised the example of teaching about the 
solar system, which is in the grade-nine unit, Space Exploration. Interestingly, Monica shifted the focus of our conversation from force and motion to force and structures, even while we engaged in our discussion about force. That suggests that her ideas about what it means to be a science teacher are influenced by the science curriculum she teaches, which in turn may have influenced her $\mathrm{PPCK}$ related to force and motion ideas. In summary, the participants' references to the pPCK related to teaching force and motion topics appear to be shaped largely by the topics they encountered in the science program of study that they were teaching. This is evident from the diverse selection of related topics they selected for our conversations, as well as from the ways they approached these topics for teaching. This suggests that the ways science methods courses prepare teachers to teach science at junior and senior high schools might best be organized as separate science methods courses for each level, with substantial opportunities specifically related to the science curriculum topics educators are expected to teach.

\section{Role of Experience in Shaping pPCK}

Previous research has identified teaching experience as a deciding factor in the development and overall quality of science PCK (e.g., Gess-Newsome, 2015; Kind, 2015; Lee and Luft, 2008; Loughran, Milroy, Berry, Gunstone \& Mulhall, 2001; Magnusson, Krajacik, \& Borko, 1999; Park and Oliver, 2006; van Driel, Verloop \& de Vos, 1998). However, there had been a need for defining experience precisely and collecting evidence of experience as factor to influence development of PCK. The above findings point to the ways in which the participant teachers developed their pPCK related to force and motion largely as a result of their experience of teaching these topics, and not by overall teaching experience. All four participants indicated that they did not learn content knowledge about force and motion topics when learning to teach during their teacher education programs. With the exception of Jason, none of the participants studied physics at an advanced level. Kevin took a physics course during undergraduate study, but Dave and Monica did not study any physics after high school. This suggests that participants' $\mathrm{pPCK}$ is grounded in their practice of teaching force and motion concepts and is an aspect of their practical knowledge. Moreover, experienced science teachers' pPCK provides a structure for the knowledge that we can hope a science teacher needs to develop in order to become an effective teacher. This suggests the usefulness of exposing pre-service science teachers to examples of documented pPCK, and using the frameworks such as Co-Res and PaP-eRs developed by Loughran et al. (2004, 2006).

\section{CONCLUSION AND IMPLICATIONS}

As discussed above, the research shows that the pPCK of the participant teachers is shaped by the prescribed curriculum that they teach. This has implications for teacher education programs design, specifically the way science methods courses are offered for junior and senior high science teachers. This research points to the need for designing separate science methods courses for junior and senior high school curriculum.

The research methods used in this research study are not new, but how they were used here is innovative, in particular with respect to the data analysis methods. Polkinghorne's (1995) suggested narrative analysis method, however, this research provides a step-by-step technique to work with the raw transcript data for narrative configuration (developing stories). Further, using the conceptual framework (comprehensive topicspecific science PCK) to identify narrative fragments, which were then woven together to develop a topicstory (that is, a story of teaching a single science topic) offered a unique way of developing stories of teaching that can reveal aspects of pPCK. The triangulation of narrative data was also distinctive. Narrative fragments identified in topic-stories were woven together to perform the narrative analysis while merging data collected for various force and motion topics. The analysis methods used in this study present implications for future research on teachers' PCK, particularly topicspecific science PCK. These methods can certainly be useful for future studies of teachers' knowledge, to triangulate data using multiple stories in a narrative inquiry.

This work provides a foundation for future research. Similar studies on other science topics will expand the substantive depth and findings of pPCK, which are required to understand the $\mathrm{PCK}$ as it appears in the science teacher's practice of teaching specific science topics. This line of research can add to the literature on pPCK by providing rich examples of the documented pPCK of individual science teachers in various topic areas, to guide the development of the science teacher education curriculum.

\section{REFERENCES}

Alonzo, A. C., \& Kim, J. (2015). Declarative and dynamic pedagogical content knowledge as elicited through two video-based interview methods. Journal of Research in Science Teaching, 53(8), 1259-1286. https:// doi.org/10.1002/tea.21271

Azam, S. (2015). Stories of teaching force and motion: A narrative inquiry into pedagogical content knowledge of science teachers (Unpublished doctoral thesis). University of Calgary, Alberta, Canada.

Azam, S. (2019). Distinguishing topic-specific professional knowledge from topic-specific PCK: A 
conceptual framework. International Journal of Environmental \& Science Education, 14(5), 281-296. Retrieved from http://www.ijese.net/makale_ indir/IJESE_2122_article_5d42f3cf31913.pdf

Carlson, J., \& Daehler, K. R. (2019). The refined consensus model of pedagogical content knowledge in science education. In A. Hume, R. Cooper \& A. Borowski (Eds.), Repositioning pedagogical content knowledge in teachers' knowledge for teaching science (pp. 77-92). Springer. https: / / doi.org/10.1007/978-981-13-5898-2

Clandinin, D. J. (1986). Classroom practices: Teacher images in action. Falmer Press.

Clandinin, D. J. (1988). Understanding research on teaching as feminist research. Paper presented at the meeting of the Canadian Society for the Study of Education, Windsor, Ontario.

Connelly, F. M., \& Clandinin, D. J. (1986). On narrative method, personal philosophy, and narrative unities in the story of teaching. Journal of Research in Science Teaching, 23(4), 293-310. https://doi.org/10.1002/ tea.3660230404

Connelly, F., \& Clandinin, D. (1988). Teachers as curriculum planners: Narratives of experience. OISE Press.

Cooper, R. (2019). Reimagining the existing. In A. Hume, R. Cooper \& A. Borowski (Eds.), Repositioning pedagogical content knowledge in teachers' knowledge for teaching science (pp. 115-116). Springer. https:/ / doi.org/10.1007/978-981-13-5898-2

Court, J. E. (1993). Free-Body diagrams revisited I. The Physics Teacher, 31(7), 104-108. https://doi.org/ 10.1119/1.880342

Cooper, R., \& van Driel, J. H. (2019) Developing research on PCK as a community. In: Hume A., Cooper R., Borowski A. (eds) Repositioning pedagogical content knowledge in teachers' knowledge for teaching Science. Springer. 5898-2_14

de Jong O., \& van Driel J. (2001) The development of prospective teachers' concerns about teaching chemistry topics at a Macro-micro-symbolic Interface. In: H. Behrendt et al. (Eds.), Research in Science Education - Past, Present, and Future. Springer.

Driver, R., Squires, A., Rushworth, P., \& WoodRobinson, V. (1994). Making sense of secondary science: Research into children's ideas. New York, NY: Routledge.

Elbaz, F. (1981). The teacher's practical knowledge: Report of a case study. Curriculum Inquiry, 11(1), 43-71.

https:/ / doi.org/10.1080/03626784.1981.11075237

Elbaz, F. (1983). Teacher thinking: A study of practical knowledge. Nichols publishing.
Elbaz, F. (1991). Research on teacher knowledge: The evolution of a discourse. Journal of Curriculum Studies, 23(1), 1-19. https://doi.org/10.1080/ 0022027910230101

Fenstermacher, G. D. (1994). The knower and the known: The nature of knowledge in research on teaching. In L. Darling-Hammond (Ed.), Review of Research in Education (pp. 3-56). American Educational Research Association. https://doi.org/10.3102/ 0091732 X020001003

Gess-Newsome, J. (1999). PCK: An introduction and orientation. In J. Gess-Newsome \& N. Lederman (Eds.), Examining PCK: The construct and its implications for science education (pp. 3-20). Kluwer.

Gess-Newsome, J. (2015). A model of teacher professional knowledge and skill including PCK: Results of the thinking from the PCK Summit. In A. Berry, P. Friedrichsen \& J. Loughran (Eds.), Reexamining pedagogical content knowledge in science education (pp. 28-42). London: Routledge. https://doi.org/10.4324/9781315735665

Gess-Newsome, J., \& Lederman, N. G. (1993). Biology teachers' perceptions of subject matter structure and its relationship to classroom practice. Journal of Research in Science Teaching, 32(3), 301-325. https:/ / doi.org/10.1002/tea.3660320309

Grossman, P. (1989). A study of contrast: Sources of pedagogical content knowledge for secondary English. Journal of Teacher Education, 40(5), 24-32. https:/ / doi.org/10.1177/002248718904000504

Gudmondsdottir, S. (1991). Story-maker, story-teller: Narrative structures in curriculum. Journal of Curriculum Studies, 23(3), 207-218. https:/ / doi.org/ $10.1080 / 0022027910230301$

Gudmundsdottir, S. (1995). The narrative nature of pedagogical content knowledge. In $\mathrm{H}$. McEwan \& K. Egan (Eds.), Narrative in teaching, learning and research (pp. 24-38). Teachers College Press.

Gudmundsdottir, S. (1998). Introduction to the theme issue on "narrative perspectives on research and teacher education." Teaching and Teacher Education, 13(1), 1-3. https://doi.org/10.1016/S0742051X(97)88229-7

Gudmundsdottir, S. (2013). Story-maker, storyteller: Narrative structures in curriculum. In C. J. Craig, P. C. Meijer, \& J. Broechmans (Eds.), Teacher thinking to teachers and teaching: The evolution of a research community (pp. 141-156). Emerald Group.

Halloun, A., \& D. Hestenes (1985) Common-sense concepts about motion. American Journal of Physics, 53(1), 1056- 1065. https:/ / doi.org/10.1119/1.14031

Hashweh, M. Z. (1987). Effects of subject-matter knowledge in the teaching of biology and physics. Teaching and Teacher Education, 3, 109-120. https:/ / doi.org/10.1016/0742-051X(87)90012-6 
Hashweh, M. Z. (2006). Teacher pedagogical construction: A reconfiguration of pedagogical content knowledge. Teachers and Teaching, 11, 273292. https:/ / doi.org/10.1080/13450600500105502

Henze, I., van Driel, J. H., \& Verloop, N. (2008). Development of experienced science teachers' pedagogical content knowledge of models of the solar system and the universe. International Journal of Science Education, 30(10), 13211342 https:/ / doi.org/10.1080/09500690802187017

Kind, V. (2015). On the beauty of knowing then not knowing. In A. Berry, P. Friedrichsen \& J. Loughran (Eds), Re-examining Pedagogical Content Knowledge in Science Education (pp. 178- 195). Routledge.

Kirschner, S., Borowski, A., Fischer, H. E., GessNewsome, J., \& von Aufschnaiter, C. (2016) Developing and evaluating a paper-and-pencil test to assess components of physics teachers' pedagogical content knowledge. International Journal of Science Education, 38(8), 1343-1372. https:/ / doi.org/10.1080/09500693.2016.1190479

Lee, E., \& Luft, J. A. (2008). Experienced secondary science teachers' representation of pedagogical content knowledge. International Journal of Science Education, 30(10), 1343-1363. https://doi.org/ $10.1080 / 09500690802187058$

Lincoln, Y., \& Guba, E. (1985). Naturalistic inquiry. Sage Publications.

Loughran, J., Milroy, P., Berry, A., Gunstone, R., \& Mulhall, P. (2001). Documenting science teachers' pedagogical content knowledge through papers. Research in Science Education, 31(2), 289-307. https:/ / doi.org/10.1023/A:1013124409567

Loughran, J., Mulhall, P., \& Berry, A. (2004). In search of pedagogical content knowledge in science: Developing ways of articulating and documenting professional practice. Journal of Research in Science Teaching, 41(4), 370-391. https://doi.org/10.1002/ tea.20007

Loughran, J., Berry, A., \& Mulhall, P. (2006). Understanding and developing science teachers' pedagogical content knowledge. Sense. https: / / doi.org/10.1007/978-94-6091-821-6

Magnusson, S., Krajacik, J., \& Borko, H. (1999). Nature, sources, and development of PCK for science teaching. In J. Gess-Newsome \& N. G. Lederman (Eds.), Examining PCK: The construct and its implications for science education (pp. 95-120). Kluwer Academic Press.

Marks, R. (1990). Pedagogical content knowledge: From a mathematical case to a modified conception. Journal of Teacher Education, 41(3), 3-11. https: / / doi.org/10.1177/002248719004100302

Nilsson, P., \& Karlsson, G. (2019) Capturing student teachers' pedagogical content knowledge (PCK) using CoRes and digital technology, International Journal of Science Education, 41(4), 419-447. https:/ / doi.org/10.1080/09500693.2018.1551642

Özden, M. (2008). The effect of content knowledge on pedagogical content knowledge: The case of teaching phases of matters. Educational Sciences: Theory and Practice, 8(2), 633-645. Retrieved from http:/ / oldsite.estp.com.tr/pdf/en/6948262ab2c32 4a2e79e04124491e2fdozden.pdf

Park, S., \& Chen, Y. (2012). Mapping out the integration of the components of pedagogical content knowledge (PCK): Examples from high school biology classrooms. Journal of Research in Science Teaching, 49(7), 922-941. https://doi.org/10.1002/ tea. 21022

Park, S., \& Oliver, J. S. (2008). Revisiting the conceptualization of pedagogical content knowledge (PCK): PCK as a conceptual tool to understand teachers as professionals. Research in Science Education, 38, 261-284. https://doiorg.qe2a-proxy.mun.ca/10.1007/s11165-007-90496

Polkinghorne, D. (1995). Narrative configuration in qualitative analysis. International Journal of Qualitative Studies in Education, 8, 135-153. https:/ / doi.org/10.1080/0951839950080103

Riessman, C. K. (1993) Narrative analysis. Qualitative Research Methods Series, No. 30. Sage.

Rosenkränzer, F., Hörsch, C., Schuler, S., \& Riess, W. (2017). Student teachers' pedagogical content knowledge for teaching systems thinking: Effects of different interventions. International Journal of Science Education, 39(4), 1-20. https://doi.org/ 10.1080/09500693.2017.1362603

Schmelzing, S., van Driel, J. H., Jüttner, M., Brandenbusch, S., Sandmann, A., \& Neuhaus, B. J. (2013). Development, evaluation and validation of a paper-and-pencil test for measuring two components of biology teachers' pedagogical content knowledge concerning the "cardiovascular system" International Journal of Science and Mathematics Education, 11(6), 1369-1390. https: / / doi.org/10.1007/s10763-012-9384-6

Shulman, L. S. (1986). Those who understand: Knowledge growth in teaching. Educational Researcher, 15(2), 4-14. Retrieved from http:/ / www.jstor.org/stable/1175860

Shulman, L. S. (1987a). Knowledge and Teaching: Foundations of new reform. Harvard Educational Review, 57, 1-22. https://doi.org/10.17763/ haer.57.1.j463w79r56455411

Stasinakis, P. K., \& Athanasiou, K. (2016). Investigating Greek biology teachers' attitudes towards evolution teaching with respect to their pedagogical content knowledge: Suggestions for 
their professional development. EURASIA Journal of Mathematics, Science \& Technology Education, 12(6), 1605-1617. https:// doi.org/10.12973/eurasia.2016. $1249 a$

Tamir, P. (1988). Subject matter and related pedagogical knowledge in teacher education. Teaching and Teacher Education, 4, 99-110. https://doi.org/ 10.1016/0742-051X(88)90011-X

Van Driel, J. H., Verloop, N., \& de Vos, W. (1998). Developing science teachers' pedagogical content knowledge. Journal of Research in Science Teaching, 35(6), 673-695. https://doi.org/10.1002/(SICI) 1098-2736(199808)35:6<673::AID-TEA5>3.0.CO;2-J

Van Driel, J., De Jong, O., \& Verloop, N. (2002). The development of pre-service chemistry teachers' pedagogical content knowledge. Science Education, 86, 572-590. https:// doi.org/10.1002/sce.10010

Veal, W. R., \& MaKinster, J. G. (1999). Pedagogical content knowledge taxonomies. Electronic Journal of Science Education, 3(4). http://wolfweb.unr.edu/ homepage/crowther/ejse/ ejsev3n4.html 


\section{APPENDIX A}

\section{Kevin - Transcript of a Conversation about Teaching Acceleration}

R: Do you remember any incident or event about teaching acceleration?

$\mathrm{K}:$ [Silence/thinking]

$\mathrm{R}$ : If no, can you share any general insight into your experience of teaching about acceleration?

$\mathrm{K}: \mathrm{Hmm}$... It is not a huge concept.

$\mathrm{R}$ : Or, any conditions that facilitated or provided obstacles, generally to the teaching of acceleration?

$\mathrm{K} \quad \ldots$ I think acceleration is fairly a new concepts for kids.

$\mathrm{R}$ : Do you teach this topic specifically at grade eight, in Mechanical Systems?

$\mathrm{K}$ : No... acceleration, not specifically, maybe when there is a question or a need to explain.

R: In grade seven you teach about structures and forces, but motion is a big part of understanding force, and we have to talk about motion, at some point?

$\mathrm{K}$ : Yes

$\mathrm{R}$ : So if we have to talk about motion, we need to talk about acceleration.

K: Yes, absolutely.

R: I mean we cannot understand Newton's 2nd Law without understanding acceleration.

$\mathrm{K}:$ Yeah.

$\mathrm{R}:$ There is a huge discussion on acceleration in Grade 11.

$\mathrm{K}$ : Yes, in Physics.

R: Yes, but usually there is a focus on quantitative stuff, like solving numerical problems, and the conceptual part is missing sometimes. So, do you think the conceptual understanding of acceleration is part of junior high curriculum?

$\mathrm{K}:$ Yes, for sure.

R: So, if you want your students understand to acceleration, what underlying ideas or concepts you want them to understand?

K: I think that... forces come into play hugely there... as well as mass. So, if they understand these little pieces, [they can understand acceleration] and then that is huge... ongoing... through examples and doing lots of practice, as for as calculating, and that kind of things.

R: Sometimes, students can do calculations and find answers, but they do not have a conceptual understanding of what acceleration is, or how we can accelerate objects. So, for that type of understanding, do you think they need to know something else?

$\mathrm{K}$ : No, I think if they get the idea of objects speeding up, and slowing down... acceleration and deceleration, and... maybe if they can make predictions on what would happen with gravity... no, I mean with friction forces and that kind of stuff. Then I think they are pretty good.

R: Did you experience any misconceptions or alternative ideas that your students bring to your classes?

$\mathrm{K}$ : No... I cannot think of any.

R: Actually, I experienced one, when teaching about acceleration. The difference between constant velocity and constant acceleration, I found that some of my students were not able to distinguish between the two. So sometimes if it is constant speed...

K: Oh, yeah, I think if they see graphs of that, like when I show graphs of them [constant velocity, and constant acceleration] they see a straight line versus a curved line trend, and I think they kind of get that. I mean, they all are driven in cars and have experienced when their parents drive with cruise control on the highway, when the car is accelerated on a stop light or something like that.

$\mathrm{R}$ : $\overline{\mathrm{OK}}$, great, so that is how you teach about acceleration?

K: Acceleration seems like a tricky concept, but maybe at this level it is fairly straightforward.

$\mathrm{R}$ : And, do you think using graphs is the best way to teach this?

$\mathrm{K}$ : Yes, that is one way, to show them the difference between speed, velocity, and acceleration, and that is when I show them different graphs.

$\mathrm{R}$ : Other than graphs, what instructional strategies you have used for teaching acceleration?

$\mathrm{K}$ We talk about... the idea of driving a car... [an everyday example]

$\mathrm{R}$ : Would you describe how do you use this example and what discussion questions guide classroom discussion?

$\mathrm{K}$ : Just a discussion about... when you are driving in city versus on the highway, using cruise control and a speed limit. And go on to the constant speed versus when you accelerate from a stop [red light].

R: Did you use any other resources, any technology, or any video clips to show them for this purpose? 
$\mathrm{K}:$ I do not remember.

R: OK, how do you show them graphs actually?

$\mathrm{K}$ : I have graphs in my notes, so I do not have graphs up on the board... although I would make them... because we have Geo Algebra... a program for active board. It is an online program to show quick and easy online graphs.

R: I also have used online computer simulations where you put values for certain variables like speed and time... and you get a quick online graph of the motion, easy to use in class.

K: I think I have used the epxplorelearning.com website and a gizmo for this... but I cannot think of it exactly, how I used it.

$\mathrm{R}$ : If you want, I can send you the link to the simulation that I used.

$\mathrm{K}: \mathrm{OK}$

K: Cycling, it would be another way that they would understand [objects] accelerating and decelerating.

R: You just mentioned using the example of driving, and let's suppose that your students do not have a background in driving. How will you consider your students' background when planning for teaching acceleration?

$\mathrm{K}$ : Oh, yes, there might be students who have never driven... but I think everybody... I would say that everybody in my classroom had been in a car, not maybe driven, but have felt the different acceleration and... if not, you could even talk about aeroplane and... and taking off... accelerating versus cruising speed... and that would... you know, less would have that experience, but I think everybody could take that lead from not actually pushing the gas pedal and feeling the acceleration but actually feeling the acceleration. And the odd chance where I have students who have never experienced sitting in a car... [Thinking]

$\mathrm{K}$ : Yes, I am thinking about, for example, in Pakistan, especially, in a rural school there might be half of the students who had never a chance to sit in a car.

$\mathrm{K}$ : Yeah, and that would be different if I would be teaching there... versus here.

R: So, what would you change there?

$\mathrm{K}$ : Well, any automotive transportation you can look at, you can even show videos... I guess of predatory animals like cheetahs, or a horse or something, where an animal accelerates, and then has more of a continuous speed, so going from a slow speed to that of a burst and that of acceleration and chasing... That would be really rare, but you can do that.

R: How did you assess your students to ensure that they have achieved an understanding of acceleration?

$\mathrm{K}$ : That is usually a quiz, and then there will be a unit test, pretty simple.

$\mathrm{R}$ : So, do you think you teach acceleration the way you were taught?

$\mathrm{K}:$ [Silence/Thinking]

R: Can you share anything special that happened in your class as a student which you also used later as teacher?

K: I do remember in junior high school in science class talking about... I do not remember what it was, if it was velocity or acceleration, something... whatever. I remember my teacher having a Hot Wheels track, and have it setting up high and the car coming down, kind of thing, and showing that car is moving...car is speeding up... but I did not know how... maybe we just took his words that the car started slower, and got faster, and as it went out at the flat, it slows down...so it is accelerated and then it is decelerated...because I know that we did not film it, or had a radar gun showing the speed change or anything like that.

$\mathrm{R}$ : I guess that might be because he did not have those types of technologies in class.

$\mathrm{K}$ : Yes, not in a junior high school classroom.

R: So, you are not sure how many students could see the difference... in that demonstration.

K: Yes, but I know how we did it... on such a track... if you are going down the hill or a slope, you feel the acceleration, but if they are behind the steering wheel they can experience that better.

R: So, did you ever use Hot Wheels tracks in your science class?

K: No, I never used the Hot Wheel tracks... [Laughing], but I am going to. I just never thought of it... I almost forgot. So, this is going to help.

R: Glad that our conversation helped you to recall this. Now you can use Hot Wheels in your class. 


\section{Topic-Story: Teaching Acceleration}

Kevin was unable to recall an incident or event from his teaching of acceleration, as he said that this is not "a huge concept" at the junior high school level. After much thought, he eventually said, "I think acceleration is a fairly new concept for kids," which he thought they had not yet been exposed to. He also noted that he does not deliberately teach this concept to grade eight students. He talks about the topic only when a question arises, or a discussion requires that this concept be clarified. Kevin supports the view that motion is an aspect of force, and therefore any discussion about motion is incomplete without at ast touching on acceleration. Our conversation led to the connection between acceleration and Newton's second law of motion, where Kevin pointed out that students should understand acceleration qualitatively as well as quantitatively.

I inquired about underlying concepts or ideas Kevin thinks students need to understand to grasp acceleration. After careful consideration, he said, "I think that... forces come into play hugely there... as well as mass. So, if they understand these little pieces [they can understand acceleration]." He elaborated, adding that students can understand acceleration "through examples and doing lots of practice, as far as calculating and that kind of thing."

I expressed the concern that sometimes students can do calculations and find the right answers but do not have a conceptual understanding of what acceleration is or how we can accelerate things. To ensure that students have this understanding, beyond just how to do acceleration calculations, Kevin said that he wants his students to "get the idea of objects speeding up and slowing down... acceleration and deceleration." He also thought that if his students "are able to make predictions about the role of friction in acceleration, they have a good understanding of acceleration."

Kevin was initially unable to share alternative ideas about acceleration that his students brought to class. However, when I mentioned my experience of some students not being able to distinguish between a constant velocity and constant acceleration, Kevin quickly responded that showing graphs can help to deal with this problem. He added, "If they see graphs of [two types of motion] ... [and] they see a straight line versus a curved line trend. . . [and] they get that." Then, hetalked about another strategy to help students distinguish between two types of motion using three examples: a car driven with cruise control on highway; the accelerated car [going] off the highway; and the car [stopped] at traffic lights. Kevin said that he believes that these examples are effective because even if they have no driving experience, "they have all driven in cars and have the experience of driving with their parents with cruise control on a highway."

Kevin also uses graphs and the above examples to teach about acceleration, saying, "Acceleration seems like a tricky concept, but maybe at this level it is fairly straightforward." $\mathrm{He}$ added that he uses different graphs because this "is one way to show the difference between speed. velocity, and acceleration."

Kevin was initially unable to share alternative ideas about acceleration that his students brought to class. However, when I mentioned my experience of some students not being able to distinguish between a constant velocity and constant acceleration, Kevin quickly responded that showing graphs can help to deal with this problem. He added, "If they see graphs of [two types of motion] ... [and] they see-a straight line versus a curved line trend. . . [and] they get that." Then, he talked about another strategy to help students distinguish between two types of motion using three examples: a car driven with/cruise control on highway; the accelerated car [going] off the highway; and the car [stopped] at traffic lights. Kevin said that he believes that these examples are effective because even if they have no driving experience, "they have all driven in cars and have the experience of driving with their parents with cruise control on a highway."

Kevin also uses graphs and the above examples to teach about acceleration, saying, "Acceleration seems like a tricky concept, but maybe at this level it is fairly straightforward." He added that he uses different graphs because this "is one way to show the difference between speed, velocity, and acceleration."
Goals of

Teaching

Acceleration

Conceptual

Understanding

of Acceleration

Effective

Instructional

Strategies

Whether

acceleration

is difficult or

easy concept 
He also uses more car examples in his classroom discussion, where he asks his students the difference between driving in the city as compared to the highway using cruise control and speed limit. Then, he asks further about a car going at a constant speed as compared to when a car accelerates from a stop light. When I asked him to describe how he uses graphs in his class, Kevin said that he has "graphs in notes" (as hard copy), but that he does "not have graphs up on the board."

He also has Geo Algebra software, which is compatible with Active Board, a program he described as good for constructing "quick and easy online graphs." He stated that he has, plans to develop and use graphs on an active board in the future. This led into a conversation on other online graph simulators he has used for teaching about acceleration, which reminded Kevin of a gizmo he found on explorelearning.com, although he did not remember how he used it. He added that "bicycling... would be another way that [students] would understand the accelerating and decelerating."

I wondered what he did with students who had no experience with cars at all, and when I asked about this, we began discussing other types of acceleration experiences. He said,

Oh yes, there might be students who have never driven ... but I think everybody... I would say that everybody in my classroom has been in a car, meybe not driven, but have felt the different acceleration. He added, "You could even talk about an airplane ... taking off... [and] accelerating versus cruising speed.

He pointed out that "less [students] would have that experience [though]." Kevin explained his rationale for using these examples, saying "I think everybody could take that lead, from not actually pushing the gas paddle and feeling the acceleration but actuatly [experience] the acceleration [as a passenger]." When I queried this further, Kevin said,

Any automotive transportation you can look at, you can even show videos . . . of predatory animals like cheetahs, or a horse [racing] or something where an animal accelerates. And then [you have] more of a continuous speed so going from a slow speed to that of a burst and that of acceleration and chasing.... That would be really rare, but you can do that.

I wanted to know how Kevin assesses his students' understanding of acceleration,and he called his strategy "pretty simple," stating that he uses a quiz and later checks their understanding through a unit test. When asked to share an incident or event he remembers from his experience of being a high school science student, particularly related to acceleration, Kevin said,

I do remember in junior high school in a science class talking about... I do not remember what it was ... if it was velocity or acceleration, or something [else] ... I remember my teacher having a Hot Wheels track... and have is setting up high and car coming down... and showing that the car is speeding up. But, I do not know how [the car was speeding up].... Maybe we just took his words that the car started slower, and got faster, and as it went out at the flat, it slowed down... so, it is accelerated and then it is decelerated... because I know we did not film it, or have a radar gun showing the speed change or anything like that.

In response to the question, "Did he ever use the "Hot Wheels" tracks in his science class? He said no,but explained that he "just never thought of it... [and] almost forgot." He seemed pleased to now consider this idea and remarked, "l am going to [use them]."

\section{http://www.ejmste.com}

